To cite this Article: Ojasalo, J. \& Tähtinen, L. (2017) Digital Participation in an Open Innovation Platform: An Empirical Study on Smart Cities. INTED2017 Proceedings, pp. 10097-10106.

DOI: $10.21125 /$ inted.2017.2461

URL: https://library.iated.org/view/OJASALO2017DIG 


\title{
DIGITAL PARTICIPATION IN AN OPEN INNOVATION PLATFORM: AN EMPIRICAL STUDY ON SMART CITIES
}

\author{
Jukka Ojasalo, Lassi Tähtinen \\ Laurea University of Applied Sciences (FINLAND)
}

\begin{abstract}
The purpose of this paper is to increase knowledge of participation in collaborative innovation of cities with digital channels, as well as propose a model of digital participation system in an open innovation platform of a city. There is very little knowledge of this area is available in the existing research literature. This paper empirically addresses this knowledge gap and contributes to the literature on digital participation in collaborative innovation, innovation intermediaries and platforms, as well as urban development and Smart City literature. The results of this study have also clear practical implications particularly to urban policy makers and developers, companies and third sector organization collaborating with cities, as well as educators in the field of innovation and urban development. The empirical research method is qualitative and draws on data from in-depth interviews and co-creative multi-actor workshops. As the result, it proposes a model which shows the main methods of digital participation in an open innovation platform, namely information dissemination, actor recruitment, and idea generation, explains their nature.
\end{abstract}

Keywords: Digital participation, e-Innovation, e-Governance, Innovation platform, Smart City, Open innovation, Public innovation, Innovation intermediary, Urban development.

\section{INTRODUCTION}

The public administration has an important role in boosting innovation in the economy and at the same time, it should trigger innovation itself in the public organisations in order to increase productivity, to improve efficiency, to enhance the creation of public value and thus to meet the society challenges [1]. In conceptualizing digital cities, digital participation and various forms of community networks are critical elements in the realization of the digital city [2,3]. Digital participation is the basis by which citizens interact, share information, discuss issues and help formulate policy in digital cities [4]. Providing access to digital culture, including the Internet, e-commerce, virtual communities, etc., to a wide cross section of society could be instructive in designing modalities of interaction in digital cities [5]. The term 'digital participation' refers here to the use of information and communication technologies (ICTs) for supporting communication and interaction of individuals with other individuals, communities, and public authorities [6]. Digital participation is also often called as 'e-participation.' Digital participation reflects enhances the participation of a wider audience [7, 8, 9]. Constant and hyper-intensive online interaction and social sharing of all digital activities is enabled by integrated systems of mobile devices, computers, social media, and the Internet [10,11]. Present socio-digital practices have blurred the boundaries between presence and absence, time and space of interaction, personal and mass communication, private and public, as well as the virtual and real worlds [12].

The term "innovation platform" is defined as an approach that systematically facilitates external actors' innovation with purpose to develop solutions to platform owners' own problems and needs [13]. In this research, the platform owner refers to a city. Fostering innovation is one of the most important objectives of any city and region and also an integral part of Smart City and urban development research. Smart Cities refer territories with high capacity for learning and innovation, which is built-in the creativity of their population, their institutions of knowledge creation, and their digital infrastructure for communication and knowledge management [14]. Innovation intermediaries and platforms have a central role in many cities and regions in this process.

This paper increases knowledge of participation in collaborative innovation of cities with digital channels, as well as proposes a model of digital participation system in an open innovation platform of a city. First, this paper reviews and discusses the literature on digital participation in innovation, innovation intermediaries and platforms, as well as Smart Cities. Next, it explains the empirical method used in this study. After that, it proposes a model of digital participation system in an open innovation platform of a city. Then, it draws the final conclusions. 


\section{DIGITAL PARTICIPATION IN COLLABORATIVE INNOVATION IN THE PUBLIC SECTOR}

Digital participation in collaborative innovation in the public sector mainly relates to streams of literature, namely e-governance and e-innovation. Collaborative innovation relates to the larger concept of networked government, which in turn includes not only the effective coordination across government organizations, but also the possible integration of organizations from both the profit and nonprofit sectors into production systems designed to achieve public purposes [15]. Cities, the public sector in general, are facing the challenge of stimulating and orchestrating collaborative innovation in multi-actor networks [16].

Due to the inherent nature of governance, e-government approaches are often collaborative in nature, bringing together various units of government, private sector, nongovernment organizations, and citizens as key stakeholders [17]. Various attributes of e-governance can be mapped onto characteristic features of innovation, thus equating e-governance with an innovation in the public sector [ibid.]. Government services can be managed and offered through a variety of different forms of ICT platforms and applications [18]. This applies also to collaborative innovation. Adams et al. [ 19] proposed a framework to show the different elements, or subconstructs, of innovation management. This is called an Innovation Management Measurement Framework, and it shows that the subconstructs of innovation management are - Inputs: people, physical and financial resources, tools - Knowledge management: idea generation, knowledge repository, information flow • Innovation strategy: strategic orientation, strategic leadership - Organization and culture: culture, structure • Portfolio management: risk/return balance, optimization tool use - Project management: project efficiency, tools, communications, collaboration • Commercialization: market research, market testing, marketing and sales (ibid.).

ICT and digital participation can enhance all the above elements of innovation in the public sector (see Potnis 2010 [20]). Most innovations in public administration have an information or ICT component. ICT is interconnected in many practices in administration as information, communication represent vital resources for public service provision, for implementing public policies as well as achieving projects and programmes [21].

The literature has emphasized the role of IT, and especially internet technologies, as enablers of important product and process innovations which have positive impacts on organizational performance $[22,23]$. In particular, IT can significantly help improving the collection, management and exchange of innovation-related knowledge, and also enable researchers distributed in different research centres of a firm to easily and rapidly share knowledge assets, and in addition, it allows a better communication and exchange of knowledge among firm's employees from different functions and disciplines, and this facilitates the combination of scientific and operational knowledge from different domains, which is important for innovation [24]. IT can reduce dramatically communication and information processing costs, and for this reason they can be key enablers and facilitators of new enhanced business processes and work practices, which lead to big productivity increases, initially by reducing costs, and subsequently by enabling firms to improve important intangible aspects of existing products and services, such as convenience, timeliness, quality, etc., and also to introduce new ones [25].

Web technologies provide innovation opportunities related to marketplaces, universal supply-chain linkages, networks of relationships, external collaborations, use of forums for setting up private groups spaces and public discussion spaces, interactive media, goods and services delivery, any-time anyplace connectivity, interconnection of enterprise IS with the ones of business partners, integration of previous telecommunications networks and computing utility [26]. Web technologies can also facilitate and drive extensive innovations that change both products' core components and business model, which can be categorized into four groups, and they are: incremental innovations (small changes in products' core components and business model), modular innovations (considerable changes in products' core components but not in the business model), architectural innovations (considerable changes in the business model but not in products' core components) and radical innovations (considerable changes in both products' core components and business model) [27, 28]. Electronic networks can support and improve external innovation collaborations (e.g. with universities, research centres, firms, etc.), through which a firm gains access to specialized knowledge that can be used for designing new products, services and processes [29].

However, e-innovation has challenges as well. They include lack of an agreeable framework to accommodate the diversity of different usages, and the trend toward standardization in e-business applications [30]. Also, various structural and cultural barriers to e-governance innovation exists both 
within a government and among citizens. Structural barriers within a government include legal constraints, lack of finances, shortage of personnel and available skills, limited political and management support, lack of coordination, and technological constraints. Cultural barriers within a government encompass resistance to change, fear that innovation undermines the robustness of government, and interference with bureaucratic culture. Structural barriers among citizens cover lack of technological facilities, limited knowledge and competences, shortage of time, and failure to integrate innovation in daily routines. Cultural barriers among citizens include lack of interest, little faith in and negative image of government, no perceived usefulness, and resistance to technology [31].

\section{INNOVATION INTERMEDIARIES AND PLATFORMS}

The concept of "innovation intermediary" is used in the scientific literature and defined by several authors. Closely related term "innovation platform" is widely used by practitioners, particularly in public government, like EU, cities and regional bodies. Despite the frequent use this term in various contexts, its meaning remains rather vague.

Innovation intermediaries and platforms are needed because the systemic setting for innovation runs only with the necessary intermediaries in place that make interactions and matching of partners possible [32]. They help to minimise asymmetric information between actors related to innovation on the market [cf. 33]. In many cases, innovation intermediaries have become a public priority to support especially resource-limited SMEs. For example, SMEs often face great barriers to participate in EU's R\&D-programmes, such as administrative, financial, internal, and external barriers [34]. Innovation intermediaries are often strongly publicly funded and have non-profit structure. However, there are some examples of innovation intermediaries which have a commercial structure and operate on the basis of reward fees $t$ they receive for exchange deals between knowledge and technology supplier and customers [35]. Both innovation intermediaries and platforms typically utilize the ideas of open innovation [36], innovation networks [37], public private partnership [38], and technology transfer [39].

An innovation intermediary is an organisation that acts as an agent or broker in any aspect of the innovation process between two or more parties [40,41, 42, 43, 44, 45, 46]. The meaning of the concepts of "innovation intermediaries" and "innovation platforms" are very close to each other. Consoli and Patrucco [47] define "innovation platforms" as systemic infrastructures for the organization and coordination of distributed innovation processes that feature high degrees of complexity. The creation of an innovation platform consists in the design and establishment of architectures for interorganizational coordination of information and knowledge, and the extent of exchange across organizations.

Patrucco [48] defines innovation platforms as directed networks, that is networks where interactions do not emerge and evolve spontaneously, such as in traditional clusters and districts, but where key nodes have a driving effect on the behaviours of the other actors and shape the evolution of the system and its aggregate performance. They are characterized as organizational innovations themselves and knowledge governance form and appear as the result of complex systems dynamics (ibid.). Ojasalo $[49,50]$ empirically examined open innovation and innovation networks in Smart Cities and defines "innovation platform" as an approach that systematically facilitates external actors' innovation with purpose to develop solutions to platform owners' problems and needs. It is an approach for attracting, facilitating, and orchestrating other organizations' innovation to solve platform owners' problems. It is primarily a way to organize, rather than a virtual or physical space, even though they may be means used to facilitate the innovation of external organizations (ibid.).

\section{SMART CITY}

The term "Smart City" has become popular among urban policy makers and in the branding of cities, but what makes a city to be "smart" is somewhat unclear. Komninos [51] defines Smart Cities as territories with high capacity for learning and innovation, which is built-in the creativity of their population, their institutions of knowledge creation, and their digital infrastructure for communication and knowledge management. Based on a literature review on Smart Cities, Hollands 2008 [52]) identified the following characteristics associated to the concept. First, a Smart City is characterized by the utilization of networked infrastructures to improve economic and political efficiency and enable social, cultural and urban development. Second, it has an emphasis on business-led urban development. Third, it enhances social inclusion. Fourth, high-tech and creative industries are seen as 
drivers of growth. Fifth, it emphasizes the role of social and relational capital in urban development. Sixth, it invests in environmental sustainability.

Smart Cities emphasize the role of ICT infrastructure, although much research has also been carried out on the role of human capital/education, social and relational capital, and environmental interest as important drivers of urban growth [53]. European Smart Cities project [54] presented six axes connecting traditional regional and neoclassical theories of urban growth and development. They are called as smart economy, smart mobility, smart environment, smart people, smart living; and smart governance [55].

Zygiaris [56] brings forward the following characteristics if the concept. A smart city is efficient, sustainable and liveable. A smart city is also characterized by intellectual ability addressing several innovative socio-technical and socio-economical aspects of growth. A smart city is green. This refers to urban infrastructure for environment protection and reduction of $\mathrm{CO} 2$ emission. A smart city is interconnected, referring to broadband economy. A smart city is intelligent. This means the capacity to produce added value information from the processing of city's real-time data from sensors and activators. A smart city is also characterized by innovation and knowledge. This refers to the city's ability to raise innovation.

\section{METHOD}

This paper emerges from an ongoing 2-year research project on open innovation platforms in Smart Cities. The project addresses several objectives. One of them concerns how an open Innovation platform can relate to the public decision making processes in a city. The results shown in this paper relate to this research objective. The research method is qualitative based on data from in-depth interviews and co-creative workshops [57]. The data of this paper include 65 in-depth interviews. The interviews were audio recorded and transcribed for later analysis. The interviewees also had a chance to make drawings during the interviews. The drawings were photographed, collected, and interpreted in the analysis.

The informants of the in-depth interview come from Finland (49), Spain (5), Netherlands (2), China (3), Italy (2), Denmark (1), USA (2) and Australia (1). The informants were selected based on their expertise or experience in innovation in the cities, public procurement, Living Labs, or other type of innovation intermediaries in the city context. The interviewees include persons from the city government, private companies, 3rd sector organizations, innovation intermediaries, as well as research institutions. Interviewees selected from the city government had experience or expertise in innovation, urban development, and collaboration with private/3rd sector organizations. Interviewees selected from the private sector had experience or expertise in collaboration with cities. Similarly, interviewees from 3rd sector had experience or expertise in collaboration with the cities. Interviewees from innovation intermediaries had experience or expertise in Living Labs or facilitation of collaborative innovation networks.

Researchers interviewed were academics who have examined innovation intermediaries or urban development. Interviews took around 1-3 hours. In addition to in-depth interviews, the data of this paper include material from 4 co-creative workshop addressing innovation collaboration between cities and external actors. The data of the workshops include the transcriptions of selected parts of the workshops, notes, photos on written and drawn material during the workshops, as well as written summaries of the main conclusions of the workshops. The data were analyzed by open coding and selective coding, in terms of the grounded theory method [58].

"Open coding" or initial coding is described by Glaser [ibid., p. 56] as follows: "The goal of the analyst is to generate an emergent set of categories and their properties which fit, work and are relevant for integrating into a theory". "Selective coding" on the other hand, means that: "...analysis is guided by the core variable. Selective coding significantly delimits his [i.e. the analyst's] work from open coding, while he sees his focus within the total context he developed during the open coding". Thus, the effort moves from the general to the focused. The purpose of the "open coding" or initial coding in this study was in discovering a potential initial solution to be proposed for the existing knowledge gap, in other words, how to connect a city government and external actors for innovation collaboration. We identified a potential to propose an open innovation platform which contains an intermediary round table as a key element. With this initial idea or interpretation in mid the focus shifted to "selective coding". This included finding empirical clues from the material in hand which help in proposing the 
nature and structure of such innovation platform. As the result, we come up with a proposal of a model described in the next section (ibid.).

\section{DIGITAL PARTICIPATION IN AN OPEN INNOVATION PLATFORM: THE EMPIRICAL RESULT}

Next, based on the current empirical study on open innovation platforms, we propose a model of digital participation system in an open innovation platform. This is shown in Figure 1.

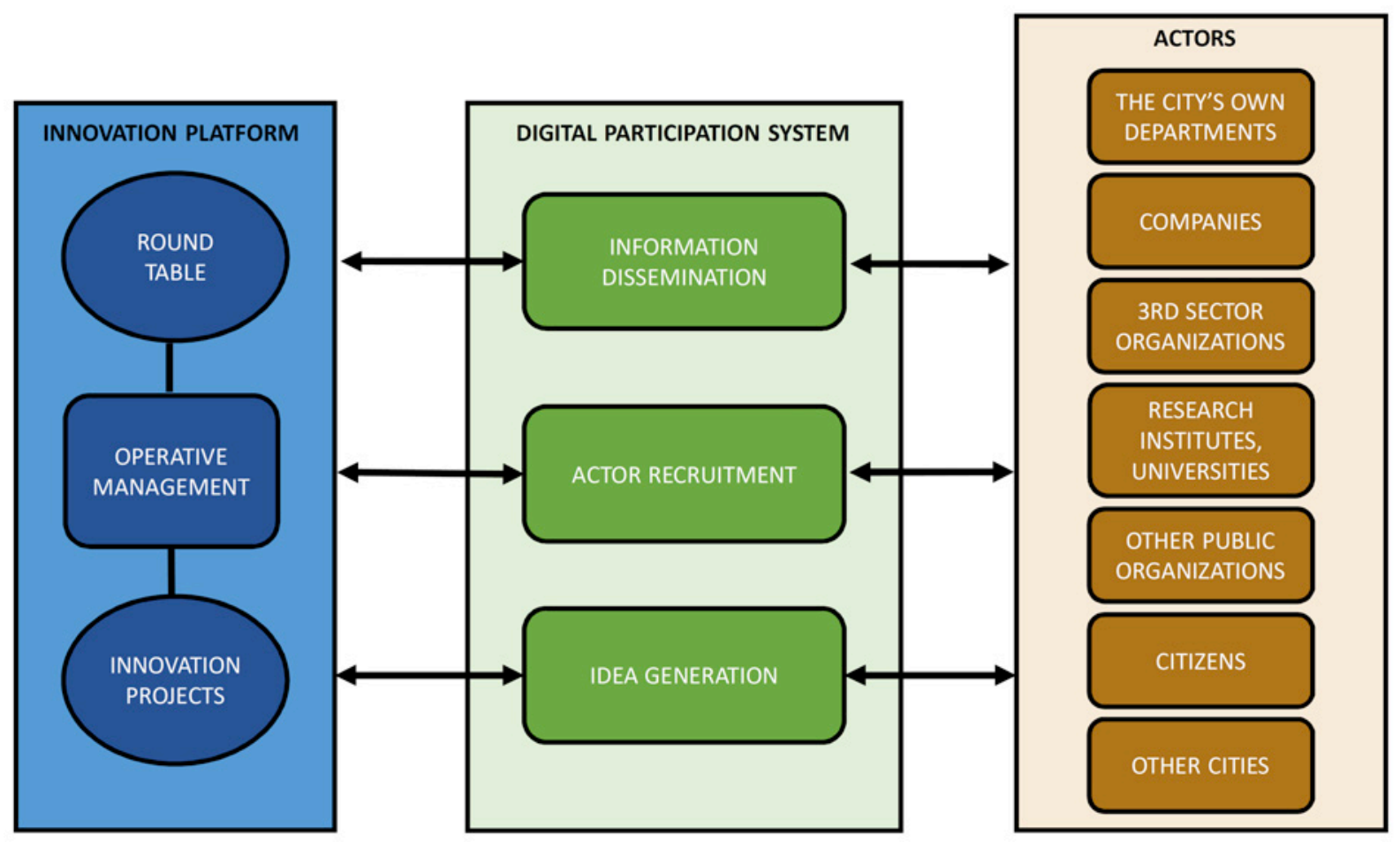

Figure 1. Digital participation system in an open innovation platform

The model consists of three main elements. They are innovation platform, digital participation, and actors [59]. Firstly, the innovation platform on the left hand side, as referred earlier, is an approach that systematically facilitates external actors' innovation with purpose to develop solutions to platform owners' problems and needs. It is an approach for attracting, facilitating, and orchestrating other organizations' innovation to solve platform owners' problems. It is primarily a way to organize, rather than a virtual or physical space, even though they may be means used to facilitate the innovation of external organizations. In our research, the platform owner refers to a city that governs the innovation platform. The main purpose of the open innovation platform in the current study is to facilitate the development of new service, products, and solutions for the city's needs. The innovation platform includes a round table, operative management, and innovation projects. Round table functions like a steering group or expert advisory group to the innovation platform. The intermediary round table includes primary members and complementary members. The primary members are carefully selected city personnel who come from the city departments and possibly the central government. Primary members have long-term involvement in the intermediary round table. The round table also has complementary members. Their involvement is usually case- or project specific, and they are invited by the primary members. Operative management refers to the daily operative management of the innovation platform. The actual service and product development is carried out in innovation projects. [60].

Actors are the second main element of the model on the right hand side. They include citizens, companies, 3rd sector organizations, research institutes and universities, the city's own departments and personnel, other public organizations, and other cities. Other public organizations may include, for example public funding agencies of R\&D, think tanks, etc. 


\subsection{Digital participation system}

Participation of actors in the collaborative innovation can be enhanced in several ways. Methods for facilitating and enabling participation of actors at the open innovation platform include special interest group meetings, digital channels, open events, open spaces, open calls, agile piloting, as well as living labs and test platforms [61]. From these different participation methods, this paper addresses digital participation and proposes a model for that.

A digital participation system is the third main element of the present model in between the innovation platform and actors. Our empirical material show that cities often lack an effective method for collecting improvement ideas on challenges of cities. A city can identify the challenges by itself, or possibly with external surveys. However, the usefulness of surveys remains often limited due to their quantitative and one-off nature, they do not offer insights. Our study reveals that cities need to have a systematic methods for maintaining dialogue between different actors, and the methods should be as real time as possible. Our data shows, that different actors should have access to the city and the opportunity join to the innovation activity through the digital participation system.

Based on our empirical material, a digital participation system should include three main elements: information dissemination, actor recruitment, and idea generation. Through the digital participation system external actors can strive to join to in-person participation in the strategic activity of the round table or emerging innovation projects. Actors can also offer their views on the city's needs and challenges through which should be addressed through the digital participation system. Actors can offer ideas either for the problem identification activity of the round table, or for the concrete ongoing projects. Ideas and requests for participation from actors are submitted through thematic categorization to the innovation platform, where they are evaluated by the operative management. A digital participation lowers the threshold to participate in the innovation activity. It also facilitates the bottom-up innovation since citizens and also the operative level employees of the city have a channel for bringing their proposals for evaluation. The operative management of the innovation platform also disseminates contemporary information about the innovation activity. This information should be categorized into themes. Consequently, it becomes easy for different actors to get a real-time snapshot on the innovation activity of the city, and also to see the potential participation opportunities to themselves. In its most simple form, a digital participation system may be a web-page which contains the three functions: information dissemination, actor recruitment, and idea generation. Next, we discuss them in more detail.

\subsection{Information dissemination}

Our data show that the information on potential innovation collaboration opportunities does not reach the audience sufficiently and through clear channels. In our model, the personnel of the operative management of the innovation platform disseminates as real-time information as possible concerning both strategic and operative aspects of the development of the city. The information should be thematically categorized to enable an easy and logical access to the relevant information. The web pages of Forum Virium Helsinki are an example of this. The participation system may also contain a map of the city or region showing the places and sites of the various ongoing and becoming innovation projects. EIT European Institute of Innovation and Technology, for example, allows an access to their innovation activity through map portal.

Similar information dissemination can be included in a digital participation system at city, country or international level. For example, the information concerning a certain part of the city, which is being developed into a smart urban environment, can be disseminated through such channels. All the becoming development projects of this part of the city can be shown, as well as all the relevant information of how to get detailed information and participate in the projects. Most importantly, the information should be logically organized in thematic categories allowing an easy and fast access to more detailed knowledge, organizations involved and key persons.

\subsection{Actor recruitment}

Actors may join to preparation or implementation of projects, work groups, discussions, pitching events, etc. through the digital participation system. In other words, the system functions as a gateway and recruitment channel to actual innovation activity. As actors have a real-time information of the ongoing and becoming projects they may offer their expertise and input to right places. In addition to operative involvement in innovation projects, they may engage in strategic level planning with the round table of the innovation platform. 
The digital participation system should introduce clearly both the ongoing and coming projects, their goals, and actors involved so far. The system should clearly indicate what kind of participants are wanted in different development projects. Thus, the potential actors can evaluate the opportunity from their perspective- the business potential, networking and learning with other participants, as well as other possible gains. For example, Amsterdam Smart City informs about the existing participants of projects, and this way aims at attracting new ones.

The criteria for joining in collaboration should be clearly expressed. Also, the interested actors need to give the required information about themselves to the operative management of the innovation platform. It evaluates the candidates based on the potential operative contribution to a single project, or based on the strategic value to the innovation platform from the holistic perspective.

\subsection{Idea generation}

Ideas for development and challenges may come from external actors or from the personnel of the city government itself. Thus, the idea generation function service both external and internal actors. External actors cover companies, $3^{\text {rd }}$ sector organizations, research institutes and universities, other public organizations such as innovation funding organizations, citizens, and other cities. Ideas may deal with needs, problems, and challenges of the city and its stakeholders. Ideas often also include suggestions for solutions. Our data indicate that, again it helps if the idea generation system is thematically organized. The operative management of the innovation platform evaluates the ideas.

The digital idea generation may also include open forums for sharing, discussing and refining ideas. Thus, the ideas can be further refined before they are evaluated by the operative management of the innovation platform.

The ideas stemming from the city's own personnel are treated similarly. The idea generation function offers a channel to everyone in the city government to bring forward their ideas, regardless the employee's position in the organization. Thus, also the front line personnel and experts have a direct channel.

The ideas may have both operative and strategic relevance. If an idea has strategic importance it can be addressed in more detail in the round table of the innovation platform. This enhances the holistic development of the city based on the long-term vision and strategy. It also integrates both external and internal actors to need-based co-creation and collaborative innovation.

\section{CONCLUSIONS}

The purpose of this paper was to increase knowledge of participation in collaborative innovation of cities with digital channels, as well as propose a model of digital participation system in an open innovation platform of a city. It was based on an extensive empirical study drawing on data from indepth interviews and co-creative multi actor workshops. As the result, it increased the knowledge of participation in collaborative innovation of cities with digital channels, and proposed a model of digital participation system in an open innovation platform of a city. The model consists of three main elements. They are innovation platform, digital participation, and actors. Participation in a collaborative innovation may happen in several ways, but this paper addressed the digital one. Through the digital participation system external actors can strive to join to emerging or existing innovation projects, as well as strategic level activity of the innovation platform. Digital participation lowers the threshold to participate in the innovation activity. It also facilitates bottom-up innovation since citizens and the operative level employees of the city have a direct channel for bringing their proposals for evaluation. The model facilitates both operative and strategic development of the city. It integrates the both external and internal actors to need-based co-creation and collaborative innovation

\section{REFERENCES}

[1] Matei, A. and Savulescu, C. (2014). Enhancing the capacity for innovation of public administration. An exploratory study on e-Governance, ICT, knowledge management in Romania, Theoretical and Applied Economics, XXI(11), 7-26

[2] Day, P. (2002). Designing democratic community networks: involving communities through civil participation. In: Tanabe, M., van den Besselaar, P., Ishida, T. (Eds.), Digital Cities II: Second Kyoto Workshop on Digital Cities (vol. LNCS 2362). Springer, Heidelberg, Germany, 86-100. 
[3] Ishida, T., (2002). Digital City Kyoto: social information infrastructure for everyday life. Communication ACM 45 (7), 76-81.

[4] Barzilai-Nahon, K. and Scholl, H.J. (2007). Similarities and Differences of e-Commerce and eGovernment: Insights from a Pilot Study. In: Sprague, R. (Ed.), 40th Hawaii International Conference on System Sciences (HICSS40). IEEE, Waikoloa/Big Island, HI., pp. 1-10.

[5] Kumar, R. and Best, M.L. (2006). Impact and sustainability of E-government services in developing countries: lessons learned from Tamil Nadu, India. The Information Society 22 (1), $1-12$.

[6] Bailey, A. and Ngwenyama, O. (2011). The challenge of e-participation in the digital city: Exploring generational influences among community telecentre users, Telematics and Informatics, 28, 204-214.

[7] Loukis, E., Peters, R., Charalabidis, Y., Passas, S. and Tsitsanis, T. (2009). Using E-maps and semantic annotation for improving citizens' and administrations' interactions, In: Paper Presented at the European and Mediterranean Conference on Information Systems 2009, July 13-14, Izmir.

[8] Macintosh, A. (2004). Characterizing E-participation in policy-making. In: Proceedings of the 37th Hawaii International Conference on System Sciences (HICSS-37), January 5-8, 2004, Big Island, Hawaii.

[9] OECD, Organisation for Economic Co-operation and Development, 2003. Promise and Problems of E-Democracy: Challenges of Online Citizen Engagement. Organisation for Economic Co-operation and Development, Paris.

[10] Rheingold, H. (2012). Net smart: How to thrive online. Cambridge, MA: MIT Press.

[11] Shirky, C. (2010). Cognitive surplus: Creativity and generosity in a connected age. London: Penguin.

[12] Baym, N. K. \& boyd, d. (2012). Socially mediated publicness: An introduction. Journal of Broadcasting \& Electronic Media, 56(3), 320-329.

[13] Ojasalo, J. (2015). Open Innovation Platform in a Smart City: Empirical Results, The Journal of American Business Review Cambridge, 4(1), 195-202.

[14] Komninos, N. (2006). The Architecture of Intelligent Cities..", Paper presented at 2nd International Conference on Intelligent Environments, Institution of Engineering and Technology, Athens, 5-6 July.

[15] Moore, M.H. 2009. Networked Government. In S. Goldsmith \& D. Kettle (Eds.), Unlocking the Power of Networks: Keys to High-Performance Government: 190-228. Washington, DC: Brookings Institution Press.

[16] Ojasalo, J. and Kauppinen, H. (2016). Collaborative Innovation with External Actors: An Empirical Study on Open Innovation Platforms in Smart Cities, Technology Innovation Management Review, 6(12), 49-60.

[17] Potnis, D.D. (2010). Measuring e-Governance as an innovation in the public sector, Government Information Quarterly, Vol. 27, 41-48.

[18] United Nations Department of Economic and Social Affairs, and Management, Division for Public Administration and Development Management, (2008). UN e-Government survey 2008, From e-Government to connected governance: Economic and social affairs.

[19] Adams, R., Bessant, J. and Phelps, R. (2006). Innovation management measurement. A review. International Journal of Management Reviews, 8, 21-47.

[20] Potnis, D.D. (2010). Measuring e-Governance as an innovation in the public sector, Government Information Quarterly, Vol. 27, 41-48.

[21] Matei, A. and Savulescu, C. (2014). Enhancing the capacity for innovation of public administration. An exploratory study on e-Governance, ICT, knowledge management in Romania, Theoretical and Applied Economics, XXI(11), 7-26 
[22] Kleis, L., Chwelos, P., Ramirez, R. and Cockburn, I. (2012). Information technology and intangible output: the impact of IT investment on innovation productivity", Information Systems Research, 23(1), 42-59.

[23] Soto-Acosta, P., Colomo-Palacios, R. and Popa, S. (2014). Web knowledge sharing and its effect on innovation: an empirical investigation in SMEs. Knowledge Management Research \& Practice, 12(1): 103-113.

[24] Popa, S., Soto-Acosta P. and Loukis, E. (2015). Analyzing the complementarity of web infrastructure and elnnovation for business value generation, Program, 50(1), 118-134.

[25] Brynjolfsson, E. and Hitt, L.M. (2000). Beyond computation: information technology, organizational transformation and business performance, Journal of Economic Perspectives, 14(4), 23-48.

[26] Zwass, V. (2003). Electronic commerce and organizational innovation: aspects and opportunities, International Journal of Electronic Commerce, 7(3), 7-37.

[27] Wu, J.H. and Hisa, T.L. (2004). Analysis of e-commerce innovation and impact: a hypercube model", Electronic Commerce Research and Applications, 3(4), 389-404.

[28] Wu, J.H. and Hisa, T.L. (2008). Developing E-business dynamic capabilities: an analysis of ecommerce innovation from I-, M- to U-commerce", Journal of Organizational Computing and Electronic Commerce, 18(2), 95-111.

[29] Popa, S., Soto-Acosta P. and Loukis, E. (2015). Analyzing the complementarity of web infrastructure and elnnovation for business value generation, Program, 50(1), 118-134.

[30] Lan, P. and Du H.H. (2002). Challenges ahead E-innovation, Technovation, 22, 761-767.

[31] Meijer, A. (2015). E-governance innovation: Barriers and strategies, Government Information Quarterly 32, 198-206.

[32] Katzy, B., Turgut, E., Holzmann, T. and Sailer, K. (2013). Innovation intermediaries: a process view on open innovation coordination, Technology Analysis \& Strategic Management, 25(3), 295-309.

[33] Spulber, D.F. (1999). Market microstructure: Intermediaries and the theory of the firm. Cambridge: Cambridge University Press.

[34] Gilmore, A. Galbraith, B. and Mulvenna, M. (2013). Perceived barriers to participation in R\&D programmes for SMEs within the European Union, Technology Analysis \& Strategic Management, 25(3), 329-339.

[35] Katzy, B., Turgut, E., Holzmann, T. and Sailer, K. (2013). Innovation intermediaries: a process view on open innovation coordination, Technology Analysis \& Strategic Management, 25(3), 295-309.

[36] Chesbrough, H. (2003). Open Innovation: The New Imperative for Creating and Profiting from Technology, Harvard Business School Press, Boston, MA.

[37] Ojasalo, J. (2008). Management of Innovation Networks -A Case Study of Different Approaches, European Journal of Innovation Management, 11(1): 51-86.

[38] Abadie, R. and Howcroft, A. (2004). Developing PPPs in New Europe. Price Waterhouse Coopers.

[39] Bessant, J., and Rush. H (1995). Building bridges for innovation: The role of consultants in technology transfer. Research Policy 24, 97-114.

[40] Howells, J. (1999). Research and technology outsourcing and innovation systems.., Industry and Innovation, 6, 111-129.

[41] Howells, J. (2006). Intermediation and the role of intermediaries in innovation, Research Policy, $35,715-728$.

[42] Lichtenthaler, U., and Ernst, H. (2008). Innovation intermediaries: Why internet marketplaces for technology have not yet met the expectations, Creativity and Innovation Management, 17, 1425. 
[43] Sieg, J.H., Wallin, M.W. and von Krogh, G.(2010). Managerial challenges in open innovation.., R\&D Management, 40, 281-291.

[44] Tran, Y., Hsuan, J. and Mahnke, V. (2011). How do innovation intermediaries add value? Insight from new product development in fashion markets, R\&D Management, 41, 80-91.

[45] Nambisan, S., J. Bacon, and J. Throckmorton (2012). The role of the innovation capitalist in open innovation, Research Technology Management, 55(3), 49-57.

[46] Klerkx, L., and C. Leeuwis. 2009. Establishment and embedding of innovation brokers at different innovation system levels: Insights from the Dutch agricultural sector. Technological Forecasting and Social Change 76: 849-60.

[47] Consoli, D., and P.P. Patrucco. 2008. Innovation platforms and the governance of knowledge: Evidence from Italy and the UK. Economics of Innovation and New Technology 17(7): 701-18.

[48] Patrucco, P.P. (2011). Changing network structure in the organization of knowledge: the innovation platform in the evidence of the automobile system in Turin, Economics of Innovation and New Technology, 20(5), 477-493.

[49] Ojasalo, J. (2015), "Open Innovation Platform in a Smart City: Empirical Results," The Journal of American Business Review Cambridge, 4(1), 195-202.

[50] Ojasalo, J. (2015), "Open Service Innovation Platform in a Smart City," in Renata Paola Dameri and Luca Beltrametti (Eds.), Proceedings of the 10th ECIE European Conference on Innovation and Entrepreneurship, University of Genoa, 17-18 September 2015, Genoa, Italy, pp. 521-528.

[51] Komninos. N. (2002). Intelligent Cities: Innovation, Knowledge Systems and Digital Spaces, Spon Press, London.

[52] Hollands, R.G. (2008). Will the real smart city please stand up?, City, 12(3), 303-320.

[53] Caragliu, A.C.D.B and Nijkamp, P. (2011). Smart Cities in Europe, Journal of Urban Technology, 18(2), 65-82.

[54] EU (2014). Mapping Smart Cities in the EU, European Union. http://www.europarl.europa.eu/RegData/etudes/etudes/join/2014/507480/IPOLITRE_ET(2014)507480_EN.pdf Accessed 14 Apr 2015.

[55] Caragliu, A.C.D.B and Nijkamp, P. (2011). Smart Cities in Europe, Journal of Urban Technology, 18(2), 65-82.

[56] Zygiaris, S. (2013). Smart city reference model: Assisting planners to conceptualize the building of smart city innovation ecosystems, Journal of the Knowledge Economy, 4(2), 217-231.

[57] Gummesson, E. (2000). Qualitative Methods in Management Research. 2nd ed., Sage Publications, California.

[58] Glaser, B.G. (1978). Theoretical Sensitivity, The Sociological Press, California.

[59] Tähtinen, L. (2017). Avoin innovaatioalusta älykkäässä kaupungissa: Hallintomalli ja osallistuminen. Opinnäytetyö. Laurea University of Applied Sciences.

[60] Ojasalo, J. and Tähtinen, L. (2016). Integrating Open Innovation Platforms in Public Sector Decision Making: Empirical Results from Smart City Research, Technology Innovation Management Review, 6(12), 38-48.

[61] Ojasalo, J. and Tähtinen, L. (2017, in print), "Participation at an Open Innovation Platform in a Smart City: Results from an Empirical Study," The Journal of American Business Review Cambridge, Vol. 23 No. 1. 